\title{
1 Epigenomic patterns reflect irrigation and grafting in the grapevine clone 'Chambourcin'
}

2 Brigette R. Williams ${ }^{1,2 *}$, Christine E. Edwards ${ }^{2}$, Misha T. Kwasniewski ${ }^{3}$, Allison J. Miller ${ }^{1,4 *}$

$3{ }^{1}$ Saint Louis University, Department of Biology, 3507 Laclede Ave, St. Louis, MO 63103, USA

$4{ }^{2}$ Missouri Botanical Garden, Center for Conservation and Sustainable Development, 4651 Shaw

5 Blvd., St. Louis, MO 63110, USA

$6{ }^{3}$ The Pennsylvania State University, College of Agricultural Sciences Department of Food

7 Science, 326 Rodney A. Erickson Food Science Building, University Park, PA 16802, USA

$8{ }^{4}$ Donald Danforth Plant Science Center, 975 North Warson Road, St. Louis, MO 63132, USA

9

$10 *$ Corresponding Authors:

11 Allison Miller

12 Office: +1 (314) 587-1232

13 amiller@,danforthcenter.org

14

15 Brigette Williams

16 brigette.williams@slu.edu

17

18 Running title: Irrigation, grafting recorded in grape epigenome

19

20

21

22

23

24

25

26

27

28

29

30 


\section{Abstract}

33 Although DNA methylation has largely been shown to be stable in plants, mounting evidence

34 indicates methylation patterns may reflect environmental sensitivity. Perennial plants experience 35 seasonal and inter-annual environmental variation, and clonal replicates of some long-lived 36 plants, including many perennial crops, survive in a broad range of environments. This makes

37 perennial crops a compelling study system to investigate links between the plant epigenome and environmental variation. In this study, we used whole genome bisulfite sequencing and small RNA sequencing to characterize the epigenome in 12 clonal replicates of the winegrape cultivar 'Chambourcin.' We asked whether DNA methylation varied in response to a full factorial combination of irrigation and grafting treatments. We found signatures of both irrigation and grafting in the 'Chambourcin' epigenome, as well as compelling evidence for a unique interaction effect whereby grafting appeared to override or mitigate epigenomic changes associated with irrigation in ungrafted vines. These findings indicate that the epigenome responds to environmental and agronomic manipulations, suggesting the epigenome might be a mechanism underlying how long-lived, clonal plants respond at the molecular level to their environment. Further research is needed to assess the potential relevance of variation in DNA methylation to plant form and function, and to address the implications of environmentallyinducible patterns of DNA methylation on the adaptive capacity of long-lived woody perennials in nature and under cultivation.

Introduction

53 Sessile organisms must be capable of surviving a wide range of environmental conditions. One

54 way this is accomplished is through phenotypic plasticity; the ability of a genetic individual to 55 produce a range of phenotypes under different environmental conditions. Recent work suggests a 56 link between phenotypic plasticity and the epigenome, which enables an individual to alter gene

57 expression through non-genetic mechanisms (Kooke et al., 2015; Zhang et al., 2018b; Perrone 58 and Martinelli, 2020). Moreover, accumulating evidence supports the epigenome as a type of 59 environmental memory in plants, whereby environmental events are recorded through

60 epigenomic modifications that the plant relies on for heightened sensitivity and faster response to 61 such events in the future (known as priming; Lämke and Bäurle, 2017). However, relatively little 
62 is known about the capacity of a single individual to remodel patterns of epigenomic variation,

63 particularly DNA methylation, in complex plant-environment interactions.

64

65

66

67

68

69

70

71

72

73

74

75

76

77

78

79

80

81

82

83

84

85

86

87

88

89

90

91

92 fluctuating environments (Rendina González et al., 2016).

The plant epigenome is a dynamic regulatory system of the genome involving covalent modifications to DNA, DNA-associating proteins (histones and histone variants) and some RNAs, and the activity of non-coding RNAs that can affect gene expression without changing the DNA sequence (Du et al., 2015). The epigenome manages genome stability and accessibility by creating and remodeling chromatin structure (Vergara and Gutierrez, 2017). DNA methylation patterns within an individual(i.e., the methylome), the most well-studied component of the epigenome, involves the establishment, maintenance, and removal of a methyl group to the 5' position on cytosines (Law and Jacobsen, 2011). DNA methylation in plants occurs in three sequence contexts ( $\mathrm{CpG}, \mathrm{CHG}$, and $\mathrm{CHH}$, where $\mathrm{H}$ represents $\mathrm{A}, \mathrm{T}$, or $\mathrm{C})$, and much of it appears to be controlled genetically (Dubin et al., 2015; Kawakatsu et al., 2016), with a large proportion being stable regardless of environment (Becker et al., 2011; Schmitz et al., 2011; Seymour et al., 2014).

Patterns of DNA methylation can also vary independently from genetic variation (Klironomos et al., 2013; Cortijo et al., 2014; Kooke et al., 2015; van der Graaf et al., 2015; Wilschut et al., 2016) and can change in response to environmental variation. For example, genome-wide remodeling of DNA methylation has been documented in response to both biotic factors (infectious pathogens, herbivory, and plant-plant competition) and abiotic factors (light, temperature, nutrient availability, and precipitation) (Verhoeven et al., 2010a; Dowen et al., 2012; Dubin et al., 2015; Secco et al., 2015; Kawakatsu et al., 2016; Alonso et al., 2019; Thiebaut et al., 2019). Furthermore, the methylomes of some plants show signatures of local adaptation and geographic provenance (Platt et al., 2015; Kawakatsu et al., 2016; Wilschut et al., 2016; Busconi et al., 2018). Such patterns of environmentally induced DNA methylation have been proposed as a form of environmental memory because they can be stably transmitted from parent to offspring (Boyko et al., 2010; Bilichak et al., 2012). Epigenomic modifications have also been transmitted clonally among ramets of a genet (parent plant), and are thought to have an important role in facilitating the persistence of clonal plants and their ability to adapt to 
94 One group in which the ability to respond to environmental variation is particularly important is

95 long-lived (perennial), woody plants. Perennial, woody plants must withstand environmental

96 variation occurring over days, weeks, years, decades, centuries (Quercus rubra L.), and even

97 millennia (Taxodium distichum; Stahle et al., 2019). Phenotypic plasticity is an important

98 mechanism enabling long-lived plants to respond to changes in environmental conditions.

99 Epigenomic responses to environmental variation is both a form of phenotypic plasticity and a

100 mechanism that may underlie phenotypic plasticity in other traits through its regulatory effects

101 on the genome (Johnson and Tricker, 2010; Kooke et al., 2015). Despite the potential importance

102 of epigenomic plasticity in the ability of long-lived, woody plants to respond to their

103 environment, the specific environmental drivers associated with epigenomic plasticity, and the

104 extent to which such plants demonstrate epigenomic plasticity are largely unknown. Most

105 previous studies of epigenomic plasticity have been conducted in annual species, including the

106 model system Arabidopsis (Johannes et al., 2009; Gao et al., 2010; Verhoeven et al., 2010; Paun

107 et al., 2010; Dowen et al., 2012; Weigel and Colot, 2012; Stroud et al., 2013; Zhong et al., 2013;

108 Herman and Sultan, 2016; Wilschut et al., 2016; Alvarez et al., 2018). Studies of epigenomic

109 plasticity in non-model woody perennials have typically employed low-resolution methods like

110 MSAP (methylation sensitive amplified polymorphism) to quantify and describe patterns of

111 epigenetic variation in experimental conditions and natural settings (Lira-Medeiros et al., 2010;

112 Herrera and Bazaga, 2011; Saéz-Laguna et al., 2014; Xie et al., 2017). These studies suggest

113 some degree of environmental sensitivity in the plant epigenome. However, it is difficult to

114 identify clear associations between changes in methylation and environmental differences in

115 such studies because the MSAP method surveys anonymous loci, for which detection partially

116 depends on conserved genetic sequences at restriction sites, rather than on the strict presence-

117 absence of methylation. Therefore, more comprehensive assessments of whole genome

118 methylation patterns are required to detect subtle changes associated with environmental

119 influences.

120

121 An approach to quantify epigenetic variation that provides greater resolution of patterns of DNA

122 methylation is bisulfite sequencing (BS-seq), where genomic DNA is subjected to high-

123 throughput DNA sequencing after being treated with bisulfite, which converts unmethylated 
124 cytosines to uracil, so all remaining cytosines are assumed to be methylated. For example, Heer

125 et al. (2018) used BS-seq to investigate the effects of the environment on methylation in Norway

126 spruce (Pinus abies). In this study, four genotypes replicated at two distinct sites showed a strong

127 signature of clonal genotype in patterns of DNA methylation but little effects of site (Heer et al

128 2018). Another study found bud break in poplar was controlled by an environmentally induced

129 epigenomic mechanism, whereby low temperatures activated a demethylase that reduced

130 methylation that then reactivated genes controlling the shift from winter dormancy to vegetative

131 growth (Conde et al., 2018). The extent to which the environment affects the epigenome of

132 plants, as well as which environmental conditions induce epigenomic plasticity, have important

133 implications for understanding how long-lived plants respond to and persist through changes in

134 their environment.

136 Clonal plants offer an ideal system for understanding the extent to which the epigenome

137 responds to environmental variation while controlling for genetic variation. Important both

138 ecologically and agriculturally, it is estimated that clones make up 40\% of all plants (Tiffney et

139 al., 1985) and more than 75\% of woody crops are clonally propagated (Miller and Gross 2011),

140 with some popular clonal varieties cultivated nearly worldwide. Epigenomic plasticity might be

141 one mechanism that allows the same clonal genotype to thrive in a wide range of climates

142 (Douhovnikoff and Dodd, 2014; Dodd and Douhovnikoff, 2016). Clonal plants provide a

143 powerful experimental system in which clonal replicates of the same genotype can be subjected

144 to environmental manipulations applied consistently over multiple years, offering an unusual

145 opportunity to characterize epigenomic plasticity in response to the environment.

147 Domesticated at least 6,000 years ago, cultivated grapevines (Vitis spp.) are among the oldest

148 clonally propagated perennial crops (Pinhas and Spiegl-Roy, 1975; This et al., 2006, Myles et al.,

149 2011). Clonally propagated grapevine cultivars are grown across very different climates, where

150 they have been shown to exhibit phenotypic variation (Dal Santo et al., 2013; Chitwood et al.,

151 2016; Young et al., 2016). Many grapevine breeders employ grafting, a surgical enhancement

152 that joins the aboveground portion of one plant (scion) to the root system of another individual

153 (rootstock). Previous research has shown that both the environment and the rootstock have

154 important effects on the phenotype of the grapevine scion (Dal Santo et al., 2013; Anesi et al., 
2015; Chitwood et al., 2016b; Young et al., 2016; Migicovsky et al., 2019), and both have consequences for a wine's terroir (the concept that a wine's flavor is of a place, derived from a specific set of environmental, soil and microbial conditions that produce stark, but consistent flavor differences between clonally propagated cultivars grown in different regions) (Sabon et al., 2002). Furthermore, prior work also indicated that different clonal lineages of the wine grape cultivar Pinot noir can be distinguished by MSAP profiles (Ocaña et al., 2013). Additionally, Xie et al. (2017) detected a signature of geographic provenance in DNA methylation in 198 Shiraz vines sampled from 22 vineyards across Australia, suggesting that the epigenome might encode a vine's terroir. However, the extent to which the environment can influence variation in DNA methylation in grapevine clones is currently unknown.

Using whole genome BS-seq in 12 replicates of a single clonal grapevine cultivar 'Chambourcin,' we investigated how patterns of DNA methylation vary in an individual genotype under different irrigation treatments, when grafted, and the interaction of these conditions. In addition, in a subset of eight of the 12 replicates, we sequenced and measured the abundance of small RNAs, which are responsible for de novo establishment and maintenance of DNA methylation through the RNA-directed DNA methylation pathway (RdDM; Matzke and Mosher, 2014; Movahedi et al., 2015; Springer et al., 2015; Lewsey et al., 2016; Bouyer et al., 2017; Tamiru et al., 2018). We addressed the following questions: (1) How does irrigation affect the methylome? (2) How does grafting affect the methylome? And (3) How does the interaction of irrigation and grafting affect the methylome? To our knowledge, this study is among the first to document epigenomic plasticity in a clonal woody individual that was subjected to multi-year experimental treatments in the field, providing information on one mechanism that might underlie plasticity in long-lived clonal plants. Furthermore, by investigating the long-term effects of environment on the epigenome of clonally propagated grapevine scions, this work has potential implications for explaining an element of the viticultural concept of terroir.

\section{Results}

\section{Whole Genome Bisulfite Sequencing.}

Genome mapping of BS-seq reads. We used whole genome BS-seq to investigate cytosine methylation among 12 clonal replicates of the winegrape cultivar 'Chambourcin' in an 
experimental vineyard at the University of Missouri Southwest Research Center (Mount Vernon, MO, USA). The 12 'Chambourcin' replicates were divided evenly among four experimental treatments (Fig. 1A): Ungrafted, Unirrigated (UG-UI); Ungrafted, Irrigated (UG-IR); Grafted, Unirrigated (GR-UI); and Grafted, Irrigated (GR-IR). Grafted vines consisted of 'Chambourcin' scions grafted to the rootstock cultivar '3309C.' Ungrafted vines are 'Chambourcin' growing ungrafted on their own roots. The irrigation treatments were initiated in 2015 after vines were established; UI vines received no irrigation from 2015 onwards and IR vines received full replacement of evapotranspiration. Leaf tissue was collected on September 25, 2017, immediately preceding harvest, placed in cryo-vials in liquid nitrogen in the field, and stored at $80 \mathrm{C}$ in the lab. Methylome profiles were generated for each of the 12 individuals. Whole-genome BS-seq reads were mapped to the Vitis vinifera reference genome (PN40024 $12 \mathrm{Xv} 3$ ). Total coverage depth of the genome was approximately $80 \mathrm{x}$, with coverage depth per replicate group estimated to be 20x (Table 1). Forty-three-point-four $-50.5 \%$ of bisulfite converted reads mapped to unique locations in the genome (see Table S1); $12.1-14.0 \%$ of reads multi-mapped. Mapping bisulfite-converted reads against the organism's chloroplast genome is an efficient and accurate method for estimating bisulfite conversion rate because chloroplast genomes are typically unmethylated (Feng et al., 2010). We mapped BS-seq reads against the Vitis chloroplast genome (NCBI GenBank RefSeq: NC_007957) and estimated the mean bisulfite conversion rate at $97.7 \%$ (see Table S1).

The total level of methylation across clonal replicates of 'Chambourcin' varied only slightly by experimental group. UG vines displayed slightly greater genome-wide methylation than GR vines (Table 2). For both UG and GR vines, IR individuals displayed slightly greater genomewide methylation than UI individuals. Genome-wide and across replicate groups, approximately

211 methylated (H represents either A, C, or T) (Table 2; see also Table S1). Cytosine methylation

212 detected in all sequence contexts in this study is similar to that typically observed in

213 angiosperms, except the proportion of methylated cytosines in the $\mathrm{CHH}$ context was slightly

214 greater than previously reported in grapevine (Niederhuth et al., 2016). 
216 Genome-wide patterns of cytosine methylation reflect grafting and irrigation. PCA was used to

217 visualize differences in methylation genome-wide among individuals. After filtering for regions

218 averaging at least a $20 \%$ difference in methylation among individuals, we retained a dataset of

$21922,464 \mathrm{bp}$ in the $\sim 500 \mathrm{Mb}$ grapevine genome (see Table S2). PC1 and PC2 capture 21\% and 17\%

220 of variation in methylation at sites among all vines (Fig. 1B). PC1 separated ungrafted (UG)

221 individuals based on irrigation treatment, whereas grafted (GR) individuals in both irrigation

222 treatments overlapped along PC1. PC2 separated grafted individuals from ungrafted individuals

223 (Fig. 1B). This PCA provides strong support for methylation patterns differing by irrigation

224 treatment in ungrafted vines, and by grafting condition.

226 Irrigated vs Unirrigated comparisons in ungrafted vines. To further investigate the extent to

227 which irrigation treatment influenced variation in DNA methylation in ungrafted vines, we tested

228 for significantly differentially methylated regions (DMRs; FDR adjusted $p$-value 0.05 in all

229 subsequent analyses) in five categories: genome-wide, intragenic regions, and in $\mathrm{CpG}, \mathrm{CHG}$, and

$230 \mathrm{CHH}$ sequence contexts. Because the classification of most annotated features have not been

231 confirmed in grapevine, we will refer to these loci as "predicted features," rather than "genes,"

232 where appropriate. (For details on all DMRs, see Table S3.)

234 In UG vines, genome-wide DMRs were often more methylated in UI vines, whereas intragenic

235 DMRs often displayed greater methylation in IR vines (Fig. 2). We identified 31 genome-wide

236 DMRs between UG (IR vs UI) vines (Fig. 1C), a majority of which (24/31) were more

237 methylated in UI conditions (Fig. 2). All genome-wide DMRs identified in UG vines were

238 unique to this experimental group comparison. Next, we focused on intragenic methylation

239 (methylation $+/-2.5 \mathrm{~kb}$ predicted gene features), and identified two DMRs with increased

240 methylation in IR conditions (Fig. 1D; Fig. 2).

242 In the analysis of patterns of $\mathrm{CpG}$ methylation ( $+/-2.5 \mathrm{~kb}$ over predicted gene features) in UG

243 vines, we detected three DMRs (Fig. 1E), two of which demonstrated greater methylation in IR

244 conditions (Fig. 2). DMRs in both $\mathrm{CHG}$ and $\mathrm{CHH}$ contexts frequently appeared within $+/-2 \mathrm{~kb}$ of

245 predicted features and, contrary to methylation levels detected in CpG context, both CHG and

$246 \mathrm{CHH}$ contexts often showed increased methylation in UI conditions (Fig. 2). Specifically, for 
247 CHG methylation, three DMRs were detected genome-wide and all were relevant to predicted

248 features (Fig. 1F). Two of these CHG DMRs overlapped predicted features directly and had

249 elevated methylation in UI conditions (Fig. 2). The other CHG DMR was located 378 bp

250 upstream of a predicted feature and it was more methylated in IR conditions. The most DMRs in

251 this comparison were detected in the analysis of CHH methylation; 61 DMRs were detected (Fig.

$2521 \mathrm{G})$, and approximately half (30/62) were either directly overlapping a predicted feature or were

253 located $<2 \mathrm{~kb}$ up- or downstream of a predicted feature. Of those $30 \mathrm{CHH}$ DMRs, the majority

254 (20/30 or 67\%) directly overlapped predicted features; three were downstream and seven were

255 upstream of predicted features. Out of the 61 total CHH DMRs, most (34/61) were more

256 methylated in the UI vines (Fig. 2). Of CHH DMRs within $+/-2 \mathrm{~kb}$ of a predicted feature (30

257 DMRs), a majority (18/30) were also more methylated in UI vines.

In summary, DNA methylation patterns in ungrafted vines displayed a signature of irrigation in all DMR categories analyzed (genome-wide, intragenic, $\mathrm{CpG}, \mathrm{CHG}$, and $\mathrm{CHH}$ ) (Fig. 1C-H).

261 This irrigation effect was characterized by greater methylation in unirrigated conditions in three

262 of the five DMR categories (genome-wide, $\mathrm{CHG}$, and $\mathrm{CHH}$ ) (Fig. 2). CHG and CHH

263 methylation are not typically associated with genes. This suggests that most increases in

264 methylation within UG vines occurred at non-genic regions when vines were unirrigated, which

265 could be relevant to transposable elements. Notably, increased methylation surrounding

266 predicted gene features in UG vines was more likely to occur under irrigated conditions.

267 Therefore, the predicted genes associated with intragenic (+/-2.5 kb) and CpG DMRs would

268 make ideal candidates for further investigation into how ungrafted 'Chambourcin' vines might be

269 relying on the epigenome to moderate a transcriptional response to irrigation.

271 Irrigated vs Unirrigated comparisons in grafted vines. The effects of irrigation on patterns of

272 DNA methylation were also compared in grafted vines. In contrast to what was observed in UG

273 vines, a majority of DMRs in GR vines displayed elevated methylation in IR conditions (Fig. 2).

274 Analysis of genome-wide methylation in GR (IR vs UI) vines identified 17 DMRs (Fig. 1C).

275 Most (10/17) of which were more methylated in UI vines (Fig. 2). None of the genome-wide

276 DMRs identified in GR vines were detected in UG vines. Zero intragenic DMRs were identified

277 (Fig. 1D). 
279 In GR vines, DMRs by sequence context displayed greater methylation in IR vines and nongenic regions experienced more changes in methylation than predicted genic regions. Analysis of patterns of $\mathrm{CpG}$ methylation (+/-2.5kb over predicted genes) detected zero DMRs (Fig. 1E). Analysis of CHG methylation revealed four DMRs (Fig. 1F), three of which were relevant to predicted features and were more methylated in IR conditions (Fig. 2). Two CHG DMRs overlapped predicted features directly and the other DMR was located $195 \mathrm{bp}$ downstream of a predicted feature. In analysis of CHH methylation, 33 DMRs were detected (Fig. 1G) and the majority (21/33) were more methylated in IR conditions (Fig. 2). Approximately half (16/33) were either directly overlapping or $<2 \mathrm{~kb}$ of a predicted feature.

Relative to UG vines, GR vines displayed far less differential methylation between irrigation conditions; only three of five DMR categories (i.e., genome-wide, $\mathrm{CHG}$, and $\mathrm{CHH}$ ) displayed significant differences (Fig. 1C, F, G). Of those three significant DMR categories, we observed greater methylation in IR vines in the $\mathrm{CHG}$ and $\mathrm{CHH}$ sequences contexts, whereas UI conditions were characterized by a majority of DMRs with increased methylation genome-wide (Fig. 2). No DMRs were detected in GR vines under contrasting irrigation conditions in either the intragenic or CpG sequence context categories (Fig. 1D, E), suggesting that genic regions in 'Chambourcin' are perhaps not being targeted in methylome remodeling when vines are grafted, in spite of different environmental conditions.

Ungrafted vs Grafted in unirrigated conditions. To determine the effect of grafting on DNA methylation, we analyzed DMRs between UG and GR vines in a common irrigation treatment.

301 First, we focused on genome-wide epigenomic variation under UI conditions; UG vines 302 displayed more methylation than grafted vines for both genome-wide and intragenic DMRs in all 303 sequence contexts (Fig. 1C, D; Fig. 2). We identified 19 genome-wide DMRs in all sequence contexts (Fig. 1C); 63\% (12/19) were more methylated in UG vines than GR vines in unirrigated conditions (Fig. 2). Analyses exploring intragenic DMRs (+/-2.5 kb) in all sequence contexts

306 identified two DMRs between UG and GR vines in UI conditions (Fig. 1D), both of which had 307 elevated methylation in GR-UI vines (Fig. 2). 
Between UG and GR vines in unirrigated conditions, sequence context specific DMRs were less consistent in methylation levels compared to the trend observed in genome-wide and intragenic DMRs (Fig. 2). When we searched $\mathrm{CpG}$ genic regions for differential methylation using a +/- 2.5 $\mathrm{kb}$ window, only three DMRs were detected (Fig. 1E). All three overlapped a gene and were more methylated in UG-UI vines (Fig. 2). Analysis of differential methylation in the CHG and $\mathrm{CHH}$ sequence contexts under unirrigated conditions showed the majority of CHG DMRs were more methylated in UG vines whereas most CHH DMRs were more methylated in GR vines. Most CHG and CHH DMRs overlapped a predicted gene feature. The analysis of CHG contextspecific methylation identified 204 DMRs (Fig. 1F) of which 97\% (197/204) were more methylated in UG vines (Fig. 2). Of the total CHG DMRs, 73\% (148/204) either overlapped or were within $2 \mathrm{~kb}$ of a predicted feature, of which 95\% (141/148) were more methylated in UG vines (Fig. 2). Most genic CHG DMRs (130/141 or 88\%) directly overlapped a predicted gene feature, accounting for 64\% (130/204) of all CHG DMRs, whereas substantially fewer CHG DMRs were found upstream (15/148 DMRs) or downstream (7/148 DMRs) of predicted features. The search for differential methylation in the $\mathrm{CHH}$ sequence context revealed only five DMRs (Fig. 1G), three of which were overlapping or downstream of predicted features. Four showed greater methylation in GR-UI vines, including two that overlapped predicted features (Fig. 2). The final CHH DMR was located 855 bp downstream of a predicted feature and was more methylated in UG-UI vines.

In summary, patterns of differential methylation in unirrigated conditions demonstrated a general trend of higher methylation in UG vines across three of five total categories of DMRs (genomewide, $\mathrm{CpG}$, and $\mathrm{CHG}$ ) (Fig. 2). The DMRs detected in the $\mathrm{CHG}$ sequence context in unirrigated conditions were particularly predominant (204) (Fig. 1F) and were overwhelmingly more methylated in UG vines (97\%, with 64\% directly overlapping predicted features) (Fig. 2). This is a potential focus of future investigation as previous research suggested that increased $\mathrm{CHG}$ methylation across genes can lead to the accumulation of $\mathrm{CpG}$ methylation over gene bodies, known as gene body methylation (gbM), which has been linked to the upregulation of some genes (Wendte et al., 2019). 
Ungrafted vs Grafted in irrigated conditions. The final comparison focused on epigenomic variation between UG and GR vines that were irrigated (IR). In contrast to the unirrigated treatment, genome-wide analyses generally revealed greater methylation in GR vines than UG vines under irrigation (Fig. 2). We identified 19 genome-wide DMRs in all sequence contexts; $68 \%(13 / 19)$ were more methylated in GR vines (Fig. 1C). Intragenically, one DMR was identified in the analysis of all sequence contexts (Fig. 1D); it was also more methylated in GR vines (Fig. 2).

Patterns of methylation by sequence context were largely defined by differences in $\mathrm{CHH}$ methylation. Analysis of the $\mathrm{CpG}$ sequence context ( $+/-2.5 \mathrm{~kb}$ of predicted gene), revealed only one DMR (Fig. 1E) and it was more methylated in UG vines (Fig. 2). In contrast to the prominent differences seen in CHG methylation in UI vines, zero CHG DMRs were detected between UG and GR vines that were IR (Fig. 1F). However, 46 CHH DMRs were found between UG and GR vines that received irrigation (Fig. 1G), 65\% (30/46) of which either overlapped or were located within $+/-2 \mathrm{~kb}$ of a predicted feature. Overall, $80 \%(36 / 45)$ of $\mathrm{CHH}$ DMRs were more methylated in GR vines (Fig. 2) and 86\% (26/30) of those located in or near a feature were more methylated in GR vines. Surprisingly, most of the feature-relevant $\mathrm{CHH}$ DMRs (14/30 or approx. 47\%) were located within $+/-2 \mathrm{~kb}$ of a predicted feature, whereas $37 \%$ $(11 / 30)$ and $16 \%(5 / 30)$ were found upstream and downstream of a feature, respectively. $\mathrm{CHH}$ DMRs that were more methylated in UG vines were located upstream of predicted features in all but one that overlapped a predicted feature. All five CHH DMRs located downstream of predicted features were more methylated in GR vines.

Overall, significant DMRs were detected between UG and GR vines that were irrigated in four out of five DMR categories. GR vines in irrigated conditions frequently showed greater methylation than UG vines (in three of the four DMR categories: genome-wide, intragenic $(+/-$ $2.5 \mathrm{~kb}$ ), and $\mathrm{CHH}$; Fig. 2). Generally, UG and GR vines that were irrigated displayed similar differences in genome-wide methylation relative to those detected under unirrigated conditions (Fig. 1A-G) except that the fewest DMRs detected in irrigated vines were in the CHG context and the most DMRs were detected in the CHH context (Fig. 1G). In the other three DMR categories, this comparison (UI: UG vs GR) revealed either few or a moderate amount of DMRs. 
370 Taken with our results that found significant differential methylation between UG and GR vines

371 that were unirrigated, this suggests that grafting is a significant driver of DNA methylation

372 differences in 'Chambourcin' vines.

373

\section{Characterization of small RNAs (sRNA)}

375 Overview of $S R N A$. Small RNAs were characterized for eight of 12 clonal replicates used in BS-

376 seq (two replicates in each of the four experimental treatments; see Supplemental Materials). As

377 above, reads were mapped to the Vitis vinifera reference genome (PN40024 12Xv3). We

378 conducted de novo cluster identification and analyses (quantitation and annotation), and

379 generated read counts of sRNA for each sample (Table S5). The 21-nt size class of sRNAs

380 (known as micro RNAs, or miRNAs, that can directly regulate gene expression) was most

381 abundant, followed by the 24-nt class (known for their role in directing DNA methylation

382 activities and targeting transposons for silencing) (Lewsey et al., 2016; Hardcastle et al., 2018).

383 Less than $25 \%$ of all sRNAs mapped within predicted gene features (mRNA, gene bodies, and

384 CDS). All sRNA loci intersected with methylated DNA in at least one sequence context in all

385 experimental groups (Table S6).

Differential expression analysis of $s R N A$. The broader pattern detected in differential expression

388 (DE) analysis of sRNA was similar to that observed in analyses of methylation. DE sRNAs varied both by irrigation and grafting treatment. Overall, very few significantly DE sRNA mapped to genes (only eleven sRNA, in total) (Fig. 1H; Table S4). In a comparison of UG and GR vines that were unirrigated, three significantly DE sRNA were detected. All three overlapped predicted genes and displayed higher expression in UG vines. A comparison of IR: UG vs GR

393 vines again detected three significantly DE sRNA, which also overlapped predicted genes; these sRNA had higher expression in GR vines. There were no common DE sRNA between UI and IR conditions. DE sRNA were also found in a comparison of UG-IR vs UG-UI vines (Fig. 1H); five significantly DE sRNA were detected and overlapped predicted genes, two of which were more to our observations of DE sRNA in UG vines, we detected zero significantly DE sRNA in a comparison of GR-IR and GR-UI vines (Fig. 1H). The few DE sRNA detected in this study are consistent with published results from other work in grapevine (Zombardo et al., 2020). 


\section{Discussion}

403 In this study, we assessed methylome remodeling in 12 clonally replicated scions of the hybrid

404 winegrape cultivar 'Chambourcin.' We observed that the 'Chambourcin' methylome is sensitive

405 to both irrigation and grafting. Ungrafted vines showed a significant effect of irrigation treatment

406 whereas grafted vines showed patterns distinct from ungrafted vines but with little effect of

407 irrigation treatment. These results suggest that grafting might influence epigenomic sensitivity to

408 environmental variation (e.g., water availability). We also detected differences in expression of

409 sRNAs in response to the treatments that were consistent with the patterns seen in DNA

410 methylation. These data indicate that irrigation and grafting affect the epigenome of a clonal

411 grapevine.

412

413 The Chambourcin methylome is plastic in response to irrigation treatment

414 The largest difference in methylation between 'Chambourcin' clones was measured in UG vines 415 exposed to different irrigation treatments (Figs. 2 and 3). Some previous studies have detected

416 effects of water availability on the epigenome of plants (Hubbard et al., 2014; Rico et al., 2014;

417 Lafon-Placette et al., 2018; Li et al., 2020); however, a drought treatment did not alter

418 methylation in Arabidopsis (Ganguly et al., 2017). Although we did not impose a drought

419 treatment, the vines in this study experienced contrasting levels of irrigation for three growing

420 seasons prior to when they were sampled, where half of the replicates received full replacement

421 of evapotranspiration versus the other half which experienced periodic drought stress under

422 natural conditions. Therefore, rather than reflecting an immediate cause-effect relationship

423 between environment and methylation, differences in methylation that correspond to irrigation

424 treatment in UG vines likely represent the cumulative effect of nearly three years of irrigation

425 differences on the epigenome. The hypothesis for a gradual divergence in the methylome based

426 on consistent pressure(s) from ecologically relevant factors is further supported by previous work

427 that has identified an epigenomic signature of geographic provenance (Busconi et al., 2015;

428 Dubin et al., 2015; Kawakatsu et al., 2016; Xie et al., 2017), as well as evidence that suggests

429 this effect could be a form of epigenomically based memory (Avramova, 2015). The ability for a

430 long-lived plant to maintain an epigenomic record in response to the long-term environmental 
431 conditions that it experiences might allow it to perform optimally in the specific environmental

432 conditions in which it grows.

\section{The Chambourcin methylome bears a signature of grafting}

435 The 'Chambourcin' methylome also bears a distinct signature of grafting, a result previously 436 reported in studies in herbaceous plants (Wu et al., 2013; Cao et al., 2016; Kasai et al., 2016;

437 Lewsey et al., 2016). The effect of the initial graft is traumatic to the plant (Melnyk, 2017) and

438 elicits a multitude of genome-regulatory responses, but it also requires long-term management of 439 molecular communication between different genomes, similar to what occurs in interspecific-

440 hybrids. This result is concordant with previous research in different systems that has shown that 441 genome-genome interactions result in an epigenomic signature, for example, in interspecific 442 hybrids (Gaut et al., 2007; Landry et al., 2007; Ishikawa and Kinoshita, 2009; Wu et al., 2013;

443 Cara et al., 2019) and in allopolyploids (Springer et al., 2015). One implication of the graft444 associated epigenomic variation reported here is that specific scion genotypes could be epigenomically predictable based on the rootstock to which they are grafted. It would be interesting to investigate whether different rootstocks produce specific epigenotypes, whether

447 rootstock-mediated epigenomic changes in the shoot are specific to the scion genotype or vary 448 based on the scion, whether epigenomic modifications in the scion underlie predictable scion phenotypes, whether phenotypic stability is linked to epigenotypes generated by specific scionrootstock combinations, and whether rootstock effects on scion methylation vary based on 451 location. Furthermore, previous work in Arabidopsis has shown that it is possible for graft452 inducible epigenomic modifications to be preserved from a grafted parent plant to seed offspring, 453 which is linked to heritable phenotypes in the offspring (Virdi et al., 2015). If this is also true for 454 woody clones, selection of desirable phenotypes from different combinations of grafted 455 individuals in such species with long generation times could expedite the process of cultivar 456 development in perennial crops. This is especially interesting to consider for wine grapes, where 457 plant breeders might be able to enhance a cultivar's terroir through epigenomically assisted 458 selection of environmental inputs and clonal propagation of specific vines. 
461 Perhaps the most striking result of this study is in the interaction effect of irrigation and grafting

462 on DNA methylation. The epigenome of ungrafted 'Chambourcin' exhibits a plastic response to

463 contrasting irrigation conditions, but this epigenomic plasticity is constrained by the effect of

464 grafting, observed as more consistent patterns of methylation in grafted vines. Although the

465 practice of grafting in grapevine began as a way to protect grapevine roots from pests and

466 pathogens, through its effect on the epigenome, grafting might provide additional viticultural

467 benefits by stabilizing the vine's phenotype and dampening its epigenomic response to different

468 environmental conditions. This reduced epigenomic plasticity in a grafted scion might result in

469 greater predictability of vine performance for agriculturally important traits like berry quality and

470 yield in spite of environmental perturbations like variable precipitation. However, that grafting

471 might act as a stabilizing or constraining force on a clonal grapevine scion's epigenome exposed

472 to different environments generates additional questions surrounding whether and how this might

473 also alter a vine's terroir, which should be the subject of additional study.

\section{Dynamic vs static DNA methylation in plants}

476 Across the 'Chambourcin' genome, a small but significant portion of the methylome showed

477 differences under experimental treatments (a total of 454 DMRs across the $\sim 500 \mathrm{Mb}$ grapevine

478 genome; Table S3). Although some studies have reported lability of DNA methylation in

479 response to the environment, other studies have reported stability of DNA methylation in plants

480 in variable environments (Niederhuth and Schmitz, 2014; Hagmann et al., 2015). We

481 acknowledge that this is perhaps partially due to the challenge of identifying a small number of

482 sites that differ in environmentally sensitive DNA methylation relative to the vast majority of

483 stable methylation across the genome in plants (i.e., faithfully maintained within an individual

484 and heritable between individuals). Another factor that may complicate the detection of

485 environmentally responsive methylation is the biological noise present in plant DNA methylation

486 data (van der Graaf et al., 2015), particularly since DNA methylation is a quantitative

487 characteristic (measured as a proportionate value for each cytosine locus) and its measurement

488 can be affected by the depth of sequencing achieved (Ziller et al., 2015). Another consideration

489 is that DNA methylation can accumulate over time and cumulative epigenomic changes in clonal

490 individuals exposed to consistent treatment(s) over multiple years (e.g., irrigation, grafting)

491 might yield detectable signals that are not observed in shorter-term experiments. In the present 
492

493

494

495

496

497

498

\section{9}

500

501

502

503

504

505

506

507

508

509

510

511

512

513

514

515

516

517

518

519

520

521 Furthermore, future work should also focus on how grafting might engage a plant's epigenome,

522

study, we were able to detect an effect of experimental treatment on epigenomic variation by employing a single replicated genotype (i.e., clones), to which consistent treatments were applied over multiple years, and a sequencing design that ensured sufficient sequencing of replicates to achieve adequate depth of coverage and genome coverage. We recommend that future studies take these aspects of experimental design into account when investigating the effects of environment on variation in DNA methylation.

\section{Conclusions and Future Directions}

In this study, we provide evidence for epigenomic plasticity in the grapevine clone 'Chambourcin': clonal replicates produce consistent, distinguishable variation in methylation patterns under different environmental treatments (irrigation) and agricultural practices (grafting). This epigenomic plasticity is likely to play an important role in the persistence of long-lived, clonal plants like grapevine; however, it is still largely unexplored in non-model systems and even less explored in clonal woody perennials in both natural and agricultural settings. Therefore, future work should focus on long-lived, clonal species in both natural populations and in orchards or vineyards. Natural experiments provide an opportunity to directly interrogate the establishment and structuring of epigenomic variation in nature, whereas the inclusion of established orchards and vineyards will allow researchers to explicitly investigate the capacity for genetically identical woody clones to respond epigenomically to environmental variation.

Currently, little is known regarding how epigenomic plasticity varies by genotype, how it is shaped in long-lived individuals under natural conditions, what role it plays in stress memory in perennials, and whether it responds when individuals are moved to common locations. An ideal study would track patterns of epigenomic variation in multiple clonal lineages growing in both natural populations and transplanted in a common garden. Such a design would provide an opportunity to differentiate among the effects of clonal genotype, geographic provenance, and the current environment on shaping patterns of epigenomic variation. thereby altering or stabilizing the phenotype. An important area of inquiry will be whether the 
523 genetic identity of the clonal rootstock has a unique effect on the epigenome and/or phenotype of

524 a scion, or if the act of grafting confers a generalized signature on the epigenome and, perhaps,

525 phenotypic stability of a scion. Therefore, one target should be to answer questions such as: Can

526 a signature in the methylome be detected by rootstock identity among multiple genetic lineages

527 of rootstock? Or is there a signature in the methylome that is only detected in the scion at the

528 resolution of a generalized grafting effect? And, how does this influence the stability or plasticity

529 of a grafted scion's epigenome when exposed to different experimental environments? By

530 focusing on these types of questions and experiments we can improve our understanding of how

531 epigenomic variation is generated and structured in diverse plant systems and what is its

532 relationship to phenotypic variation and/or stability, as well as how plants respond to and

533 remember their environment, all of which have broad implications for ecology, evolution, and

534 agriculture.

535

536 Methods

537 Sample collection. Experimental grapevines located at the University of Missouri's Southwest

538 Research Center (Mt. Vernon, MO) were sampled just prior to berry harvest in September 2017.

539 Vines were planted in 2009 and are either the ungrafted wine cultivar 'Chambourcin' or

540 'Chambourcin' grafted to rootstock 3309C (Vitis riparia $\mathrm{x}$ V. rupestris). Vines have been

541 maintained in either full irrigation or no irrigation conditions since 2015. Twelve vines were

542 sampled that represent four experimental treatment combinations (ungrafted, full irrigation;

543 ungrafted, no irrigation; grafted, full irrigation; grafted, no irrigation) with three biological

544 replicates per treatment group. The youngest leaf tissue on two shoots per vine was collected into

545 cryovials and stored in liquid nitrogen for transport to a $-80^{\circ} \mathrm{C}$ freezer.

546

547 DNA extraction, bisulfite library construction, and sequencing. A modified CTAB protocol

548 adapted from Azmat et al. (2012) was used to extract DNA from leaf tissue. DNA was quantified 549 using a Qubit DNA High Sensitivity kit (Cat no. Q33231). Whole Genome Bisulfite Sequencing 550 (WGBS) libraries were prepared using a ZR Pico Methyl-Seq ${ }^{\mathrm{TM}}$ Library Prep Kit (Cat no. 5456), 551 then validated and quantified using a HS DNA kit on an Agilent 2100 BioAnalyzer. Libraries

552 were pooled into three groups of four samples each and sequenced (2x150bp) on three lanes of

553 Illumina HiSeq 4000 at Duke Center for Genomic and Computational Biology. 
WGBS quality filtering, read alignment, and methylation extraction. Bisulfite (BS) conversion rate was estimated by mapping sample reads against the Vitis chloroplast genome

557 (see Supplemental Table S1). Quality filtering, alignment, deduplication, and methylation calling was performed in Bismark (Babraham Bioinformatics, Babraham Institute, Cambridge, UK; Krueger and Andrews, 2011). Vitis genome version GCF_000003745.3_12X was downloaded from NCBI. FastQC was performed before and after trimming. Reads were aligned and mapped in single-end mode and --non-directional option per Zymo recommendations. Reads were sorted in SAMtools before deduplication and methylation calling. Methylation information from both strands was combined using the --comprehensive option then output into context-specific files (CpG, $\mathrm{CHG}$, and $\mathrm{CHH})$. "coverage" files were generated with the --bedGraph option.

Genome-wide methylation and identification of differentially methylated regions. DMRs

567 were identified using SeqMonk (Babraham Bioinformatics, Babraham Institute, Cambridge,

568 UK). SeqMonk uses the Ensembl genome annotation from the 12X, INSDC

569 Assembly GCA_000003745.2 assembly (last modified 9/19/2016). Coverage files were imported

570 into SeqMonk and replicates were grouped by experimental treatment. A running window

571 approach $(25,000 \mathrm{bp}$ windows and steps), and read count quantitation identified coverage outliers

57210 above the median to be filtered. Genome-wide cytosine methylation probes were created via

573 running window (100 bp bins, 25 bp steps). In all DMR analyses, methylation over probes was

574 assessed using the "Bisulfite methylation over features" pipeline, the mean value per probe

575 reported, and Logistic Regression and EdgeR analyses were conducted and the results collated

576 (multiple testing correction was applied; FDR cutoff $p$-value 0.05). A 15x minimum depth of

577 coverage per replicate group was required in all analyses. Absolute methylation differences

578 calculated pairwise between groups were: genome-wide $\geq 20 \%$; intragenic $\geq 20 \%$; $\mathrm{CpG} \geq 10 \%$;

$579 \mathrm{CHG} \geq 10 \% ; \mathrm{CHH} \geq 10 \%$. In all analyses, DMRs within $100 \mathrm{bp}$ were grouped. Intragenic and

580 CpG DMRs were defined as +/- 2,500bp over predicted features. Analysis of CHG and $\mathrm{CHH}$

581 DMRs used the same running window probe generation protocols described above with the

582 relevant methylation-by-sequence-context coverage files. For all DMR analyses, four

583 comparisons were made: UG - IR vs UI; GR - IR vs UI; UI - UG vs GR; IR - UG vs GR. 
RNA extraction, library construction, and sequencing. RNA was extracted from the same leaf tissue as DNA using a ZR-Duet ${ }^{\mathrm{TM}}$ DNA/RNA MiniPrep Plus extraction kit (Cat. no. D7003). RNA samples were quantified using a Qubit RNA High Sensitivity kit (Cat no. Q32852). cDNA libraries were created from small RNA (sRNA) using an NEBNext® Multiplex sRNA Library Prep (set 1) kit (Cat no. E7300S/L). Libraries were validated and quantified on an Agilent 2100 BioAnalyzer System. Libraries were pooled and sequenced (1x50) on one Illumina Hiseq 4000 lane at Duke Center for Genomic and Computational Biology.

Analysis of small RNA data. FastQC was performed on sRNA reads before and after trimming and filtering. Trim Galore! was used to carry out trimming and filtering of sRNA reads (minimum score of $>$ Q20, maximum read length of 24-nt) (Martin, 2011). Alignment, annotation, and quantification of sRNAs was performed using ShortStack v3 (Axtell, 2013). Reads were mapped to Vitis genome version GCF_000003745.3_12X. The options specified were: zero mismatches, 'unique' multi-mapping alignment, $100 \mathrm{bp}$ pads, minimum coverage designated in rpm, and strand identity determination. Count files from ShortStack were uploaded into SeqMonk; probes were generated via running window, "Percentile Normalisation Quantitation" using the $50^{\text {th }}$ percentile was used to calculate the additive scaling factor. Outlier Analysis filtered sRNAs at 10 above the median. Samples were grouped into "Replicate Datastores" by experimental group. Probes were created using "Read Position Probe Generator" (100 minimum reads, 1 valid position per window). sRNAs were filtered and reported to identify overlap with predicted genomic features. Probes were saved as annotation tracks and used as "features of interest" to identify areas of overlap with DNA methylation in each sequence context. DESeq2 was used to test for differential expression of sRNAs from un-normalized count files.

609

\section{Accession numbers.}

611 Sequence data from this article will be submitted to NCBI SRA under accession numbers XXX00000000 (WGBS) and XXX00000000 (sRNA-seq).

614 Author Contributions: BW conducted the experiments and analyses, and wrote the paper. AM, 
Acknowledgements: The authors gratefully acknowledge the staff at the University of Missouri experimental vineyard. We acknowledge members of the Miller Lab group and Edwards Lab group for careful comments on previous versions of the manuscript. Funding for this work was provided by Missouri Grape and Wine Institute Research Grant to AM, BW, CE, and MK, and NSF Plant Genome Research Program grant 1546869 to AJM and MK. No conflict of interest declared.

624

625

\section{References}

626 Alonso, C., Ramos-Cruz, D., and Becker, C. (2019). The role of plant epigenetics in biotic interactions. New Phytol. 221:731-737.

Alvarez, M., Robertson, M., van Gurp, T. P., Wagemaker, N. C. A. M., Giraud, D., representation bisulfite sequencing finds epigenome-wide response to oil pollution in the foundation plant Spartina alterniflora. bioarXiv Advance Access published 2018, doi: $10.1101 / 426569$

Anesi, A., Stocchero, M., Dal Santo, S., Commisso, M., Zenoni, S., Ceoldo, S., Tornielli, G.

Avramova, Z. (2015). Transcriptional "memory" of a stress: transient chromatin and memory (epigenetic) marks at stress-response genes Advance Access published 2015, doi:10.1111/tpj.12832

Axtell, M. J. (2013). ShortStack: Comprehensive annotation and quantification of small RNA genes. $R N A$ 19:740-751. (2012). Extraction of DNA suitable for PCR applications from mature leaves of Mangifera indica L. J. Zhejiang Univ. Sci. B 13:239-243. 
Becker, C., Hagmann, J., Müller, J., Koenig, D., Stegle, O., Borgwardt, K., and Weigel, D. (2011). Spontaneous epigenetic variation in the Arabidopsis thaliana methylome. Nature 480:245-249.

Bilichak, A., Inystkyy, Y., Hollunder, J., and Kovalchuk, I. (2012). The progeny of Arabidopsis thaliana plants exposed to salt exhibit changes in DNA methylation, histone modifications and gene expression. PLoS One 7.

Bouyer, D., Kramdi, A., Kassam, M., Heese, M., Schnittger, A., Roudier, F., and Colot, V. (2017). DNA methylation dynamics during early plant life. Genome Biol. 18:179.

Boyko, A., Blevins, T., Yao, Y., Golubov, A., Bilichak, A., Inytskyy, Y., Hollander, J., Meins, F., and Kovalchuk, I. (2010). Transgenerational adaptation of Arabidopsis to stress requires DNA methylation and the function of dicer-like proteins. PLoS One 5.

Busconi, M., Colli, L., Sánchez, R. A., Santaella, M., De-Los-Mozos Pascual, M., Santana, O., Roldán, M., and Fernández, J. A. (2015). AFLP and MS-AFLP analysis of the variation within saffron crocus (Crocus sativus L.) germplasm. PLoS One 10:1-18.

Busconi, M., Soffritti, G., Stagnati, L., Marocco, A., Marcos Martínez, J., De Los, M., Pascual, M., and Fernandez, A. (2018). Epigenetic stability in Saffron (Crocus sativus L.) accessions during four consecutive years of cultivation and vegetative propagation under open field conditions Advance Access published 2018, doi:10.1016/j.plantsci.2018.09.005.

Cao, L., Yu, N., Li, J., Qi, Z., Wang, D., and Chen, L. (2016). Heritability and Reversibility of DNA Methylation Induced by in vitro Grafting between Brassica juncea and B. oleracea. Sci. Rep. 6:1-13.

Cara, N., Ferrer, M. S., Masuelli, R. W., Camadro, E. L., and Marfil, C. F. (2019). Epigenetic consequences of interploidal hybridisation in synthetic and natural interspecific potato hybrids. New Phytol. 222:1981-1993.

Chitwood, D. H., Rundell, S. M., Li, D. Y., Woodford, Q. L., Yu, T. T., Lopez, J. R., Greenblatt, D., Kang, J., and Londo, J. P. (2016a). Climate and developmental plasticity: interannual variability in grapevine leaf morphology. Plant Physiol. 170:pp.01825.2015.

Chitwood, D. H., Rundell, S. M., Li, D. Y., Woodford, Q. L., Yu, T. T., Lopez, J. R., Greenblatt, D., Kang, J., and Londo, J. P. (2016b). Climate and developmental plasticity: Interannual plasticity in grapevine leaf morphology. Plant Physiol. 170:1480-1491. 
675 Conde, D., Le Gac, A. L., Perales, M., Dervinis, C., Kirst, M., Maury, S., González-

676 Melendi, P., and Allona, I. (2017). Chilling-responsive DEMETER-LIKE DNA

677 demethylase mediates in poplar bud break. Plant Cell Environ. 40:2236-2249.

678 Cortijo, S., Wardenaar, R., Colomé-Tatché, M., Gilly, A., Etcheverry, M., Labadie, K.,

679 Caillieux, E., Hospital, F., Aury, J.-M., Wincker, P., et al. (2014). Mapping the Epigenetic

680 Basis of Complex Traits.

681 Dal Santo, S., Tornielli, G. B., Zenoni, S., Fasoli, M., Farina, L., Anesi, A., Guzzo, F.,

682 Delledonne, M., and Pezzotti, M. (2013). The plasticity of the grapevine berry

683 transcriptome. Genome Biol. 14:r54.

684 Dodd, R. S., and Douhovnikoff, V. (2016). Adjusting to Global change through clonal growth 685 and epigenetic variation. Front. Ecol. Evol. 4.

Douhovnikoff, V., and Dodd, R. S. (2014). Epigenetics: a potential mechanism for clonal plant success. Plant Ecol. 216:227-233.

Dowen, R. H., Pelizzola, M., Schmitz, R. J., Lister, R., Dowen, J. M., Nery, J. R., Dixon, J. E., and Ecker, J. R. (2012). Widespread dynamic DNA methylation in response to biotic stress. Proc. Natl. Acad. Sci. 109:E2183-E2191.

Du, J., Johnson, L. M., Jacobsen, S. E., and Patel, D. J. (2015). DNA methylation pathways and their crosstalk with histone methylation. Nat. Rev. Mol. Cell Biol. 16:519-532.

Dubin, M. J., Zhang, P., Meng, D., Remigereau, M. S., Osborne, E. J., Casale, F. P., Drewe, P., Kahles, A., Jean, G., Vilhjálmsson, B., et al. (2015). DNA methylation in Arabidopsis has a genetic basis and shows evidence of local adaptation. Elife 4:1-23.

Ensing, D. J., and Eckert, C. G. (2019). Interannual variation in season length is linked to strong co-gradient plasticity of phenology in a montane annual plant. New Phytol. 224:11841200.

Fortes, A. M., and Gallusci, P. (2017). Plant stress responses and phenotypic plasticity in the epigenomics era: Perspectives on the grapevine scenario, a model for perennial crop plants. Front. Plant Sci. 8.

Ganguly, D. R., Crisp, P. A., Eichten, S. R., and Pogson, B. J. (2017). The Arabidopsis DNA Methylome Is Stable under Transgenerational Drought Stress. Plant Physiol. 175:1893-1912. 
for epigenetic regulation of rapid responses to environmental fluctuation and phenotypic variation. Plant, Cell Environ. 33:1820-1827.

Gaut, B. S., Díez, C. M., and Morrell, P. L. (2015). Genomics and the Contrasting Dynamics of Annual and Perennial Domestication. Trends Genet. 31:709-719.

Gaut, B. S., Miller, A. J., and Seymour, D. K. (2019). Living with Two Genomes: Grafting and Its Implications for Plant Genome-to-Genome Interactions, Phenotypic Variation, and Evolution. Annu. Rev. Genet. 53:195-215.

Geng, Y. P., Pan, X. Y., Xu, C. Y., Zhang, W. J., Li, B., Chen, J. K., Lu, B. R., and Song, Z.

Hagmann, J., Becker, C., Müller, J., Stegle, O., Meyer, R. C., Wang, G., Schneeberger, K.,

Hardcastle, T. J., Müller, S. Y., and Baulcombe, D. C. (2018). Towards annotating the plant epigenome: The Arabidopsis thaliana small RNA locus map. Sci. Rep. 8:1-15.

Heer, K., Ullrich, K. K., Hiss, M., Liepelt, S., Schulze Brüning, R., Zhou, J., Opgenoorth, L., and Rensing, S. A. (2018). Detection of somatic epigenetic variation in Norway spruce via targeted bisulfite sequencing. Ecol. Evol. 8:9672-9682.

Hubbard, M., Germida, J. J., and Vujanovic, V. (2014). Fungal endophyte colonization coincides with altered DNA methylation in drought-stressed wheat seedlings. Can. J. Plant Sci. 94:223-234.

Ishikawa, R., and Kinoshita, T. (2009). Epigenetic programming: The challenge to species hybridization. Mol. Plant 2:589-599. 
Johannes, F., Porcher, E., Teixeira, F. K., Saliba-Colombani, V., Simon, M., Agier, N., Bulski, A., Albuisson, J., Heredia, F., Audigier, P., et al. (2009b). Assessing the impact of transgenerational epigenetic variation on complex traits. PLoS Genet. 5.

Johnson, L. J., and Tricker, P. J. (2010). Epigenomic plasticity within populations: Its evolutionary significance and potential. Heredity (Edinb). 105:113-121.

Kasai, A., Bai, S., Hojo, H., and Harada, T. (2016). Epigenome editing of potato by grafting using transgenic tobacco as siRNA donor. PLoS One 11:1-12.

Kawakatsu, T., Huang, S. shan C., Jupe, F., Sasaki, E., Schmitz, R. J. J., Urich, M. A. A.,

Kooke, R., Johannes, F., Wardenaar, R., Becker, F., Etcheverry, M., Colot, V., Castanon, R., Nery, J. R. R., Barragan, C., He, Y., et al. (2016). Epigenomic Diversity in a Global Collection of Arabidopsis thaliana Accessions. Cell 166:492-506.

Klironomos, F. D., Berg, J., and Collins, S. (2013). How epigenetic mutations can affect genetic evolution: Model and mechanism. Bioessays J. Advance Access published 2013, doi:10.1002/bies.201200169. Vreugdenhil, D., and Keurentjes, J. J. B. (2015). Epigenetic Basis of Morphological Variation and Phenotypic Plasticity in Arabidopsis thaliana. Plant Cell Online 27:337-348.

Krueger, F., and Andrews, S. R. (2011). Bismark: A flexible aligner and methylation caller for Bisulfite-Seq applications. Bioinformatics 27:1571-1572.

\section{Lafon-Placette, C., Le Gac, A. L., Chauveau, D., Segura, V., Delaunay, A., Lesage-}

\section{Descauses, M. C., Hummel, I., Cohen, D., Jesson, B., Le Thiec, D., et al. (2018). Changes} in the epigenome and transcriptome of the poplar shoot apical meristem in response to water availability affect preferentially hormone pathways. J. Exp. Bot. 69:537-551.

Lämke, J., and Bäurle, I. (2017). Epigenetic and chromatin-based mechanisms in environmental stress adaptation and stress memory in plants. Genome Biol. 18.

Landry, C. R., Hartl, D. L., and Ranz, J. M. (2007). Genome clashes in hybrids: Insights from gene expression. Heredity (Edinb). 99:483-493.

Lauss, K., Wardenaar, R., Oka, R., Van Hulten, M. H. A., Guryev, V., Keurentjes, J. J. B., Stam, M., and Johannes, F. (2018). Parental DNA Methylation States Are Associated with Heterosis in Epigenetic Hybrids 1[OPEN]. Plant Physiol. Ò 176:1627-1645.

Law, J. A., and Jacobsen, S. E. (2011). Establising, maintaining and modifying DNA methylation patterns in plants and animals. Nat Rev Genet. 11:204-220. 
Lewsey, M. G., Ecker, J. R., Baulcombe, D. C., Molnar, A., Melnyk, C. W., Urich, M. A., Hardcastle, T. J., Nery, J. R., and Valli, A. (2016). Mobile small RNAs regulate genomewide DNA methylation. Proc. Natl. Acad. Sci. 113:E801-E810.

Li, Y., Kumar, S., and Qian, W. (2018). Active DNA demethylation: mechanism and role in plant development. Plant Cell Rep. 37:77-85.

Li, R., Hu, F., Li, B., Zhang, Y., Chen, M., Fan, T., and Wang, T. (2020). Whole genome bisulfite sequencing methylome analysis of mulberry (Morus alba) reveals epigenome modifications in response to drought stress. Sci. Rep. 10:1-17.

Lira-Medeiros, C. F., Parisod, C., Fernandes, R. A., Mata, C. S., Cardoso, M. A., and Ferreira, P. C. G. (2010). Epigenetic variation in mangrove plants occurring in contrasting natural environment. PLoS One 5.

Loomis, E. S., and Fishman, L. (2009). A continent-wide clone: Population genetic variation of the invasive plant hieracium aurantiacum (orange hawkweed; Asteraceae) in North America. Int. J. Plant Sci. 170:759-765.

Makhrov, A. A. (2019). Decreased Evolutionary Plasticity as a Result of Phylogenetic Immobilization and Its Ecological Significance. Contemp. Probl. Ecol. 12:405-417.

Matzke, M. A., and Mosher, R. A. (2014). RNA-directed DNA methylation: An epigenetic pathway of increasing complexity. Nat. Rev. Genet. 15:394-408.

McKey, D., Elias, M., Pujol, M. E., and Duputié, A. (2010). The evolutionary ecology of clonally propagated domesticated plants. New Phytol. 186:318-332.

Melnyk, C. W. (2017). Plant grafting: insights into tissue regeneration. Regeneration 4:3-14.

Meyer, R. S., Duval, A. E., and Jensen, H. R. (2012). Patterns and processes in crop domestication: An historical review and quantitative analysis of 203 global food crops. New Phytol. 196:29-48.

Migicovsky, Z., Harris, Z. N., Klein, L. L., Li, M., McDermaid, A., Chitwood, D. H., Fennell, A., Kovacs, L. G., Kwasniewski, M., Londo, J. P., et al. (2019). Rootstock effects on scion phenotypes in a 'Chambourcin' experimental vineyard. Hortic. Res. 6. 
Myles, S., Boyko, A. R., Owens, C. L., Brown, P. J., Grassi, F., Aradhya, M. K., Prins, B., Reynolds, A., Chia, J. M., Ware, D., et al. (2011). Genetic structure and domestication history of the grape. Proc. Natl. Acad. Sci. U. S. A. 108:3530-3535.

Niederhuth, C. E., and Schmitz, R. J. (2014). Covering Your Bases: Inheritance of DNA Methylation in Plant Genomes. Mol. Plant • 7:472-480.

Niederhuth, C. E., and Schmitz, R. J. (2017). Putting DNA methylation in context: from genomes to gene expression in plants. Biochim. Biophys. Acta-Gene Regul. Mech. 1860:149-156.

Niederhuth, C. E., Bewick, A. J., Ji, L., Alabady, M. S., Kim, K. Do, Li, Q., Rohr, N. A., Rambani, A., Burke, J. M., Udall, J. A., et al. (2016). Widespread natural variation of DNA methylation within angiosperms. Genome Biol. 17:1-19.

Ocaña, J., Walter, B., and Schellenbaum, P. (2013). Stable MSAP markers for the distinction of vitis vinifera cv pinot noir clones. Mol. Biotechnol. 55:236-248.

Ong-Abdullah, M., Ordway, J. M., Jiang, N., Ooi, S. E., Kok, S. Y., Sarpan, N., Azimi, N., Hashim, A. T., Ishak, Z., Rosli, S. K., et al. (2015). Loss of Karma transposon methylation underlies the mantled somaclonal variant of oil palm. Nature 525:533-537.

Paun, O., Bateman, R. M., Fay, M. F., Hedrén, M., Civeyrel, L., and Chase, M. W. (2010a). Stable epigenetic effects impact adaptation in allopolyploid orchids (Dactylorhiza: Orchidaceae). Mol. Biol. Evol. 27:2465-2473.

Paun, O., Bateman, R. M., Fay, M. F., Hedrén, M., Civeyrel, L., and Chase, M. W. (2010b). Stable epigenetic effects impact adaptation in allopolyploid orchids (Dactylorhiza: Orchidaceae). Mol. Biol. Evol. 27:2465-2473.

Perrone, A., and Martinelli, F. (2020). Plant stress biology in epigenomic era. Plant Sci. 294.

Platt, A., Gugger, P. F., Pellegrini, M., and Sork, V. L. (2015a). Genome-wide signature of local adaptation linked to variable CpG methylation in oak populations. Mol. Ecol. 24:38233830.

Platt, A., Gugger, P. F., Pellegrini, M., and Sork, V. L. (2015b). Genome-wide signature of local adaptation linked to variable $\mathrm{CpG}$ methylation in oak populations. Mol. Ecol. 24:38233830 . 
Rendina González, A. P., Chrtek, J., Dobrev, P. I., Dumalasová, V., Fehrer, J., Mráz, P., and Latzel, V. (2016). Stress-induced memory alters growth of clonal offspring of white clover (Trifolium repens). Am. J. Bot. 103:1567-1574.

Rico, L., Ogaya, R., Barbeta, A., and Peñuelas, J. (2014). Changes in DNA methylation fingerprint of Quercus ilex trees in response to experimental field drought simulating projected climate change. Plant Biol. 16:419-427.

Saéz-Laguna, E., Guevara, M. Á., Diáz, L. M., Sańchez-Gómez, D., Collada, C., Aranda, I., and Cervera, M. T. (2014). Epigenetic variability in the genetically uniform forest tree species Pinus pinea L. PLoS One 9.

Schmitz, R. J., Schultz, M. D., Lewsey, M. G., O’Malley, R. C., Urich, M. A., Libiger, O., Schork, N. J., and Ecker, J. R. (2011). Transgenerational Epigenetic Instability is a Source of Novel Methylation Variants. Science (80-. ). 334:369-373.

Secco, D., Wang, C., Shou, H., Schultz, M. D., Chiarenza, S., Nussaume, L., Ecker, J. R., Whelan, J., and Lister, R. (2015). Stress induced gene expression drives transient DNA methylation changes at adjacent repetitive elements. Elife 4.

Seymour, D. K., Koenig, D., Hagmann, J., Becker, C., and Weigel, D. (2014). Evolution of DNA Methylation Patterns in the Brassicaceae is Driven by Differences in Genome Organization. PLoS Genet. 10:e1004785.

Springer, N. M., Lisch, D., and Li, Q. (2015). Creating order from chaos: Epigenome dynamics in plants with complex genomes. Plant Cell 28:314-325.

Stahle, D. W., Edmondson, J. R., Howard, I. M., Robbins, C. R., Griffin, R. D., Carl, A., Hall, C. B., Stahle, D. K., and Torbenson, M. C. A. (2019). Longevity, climate sensitivity, and conservation status of wetland trees at Black River, North Carolina. Environ. Res. Commun. 1:041002.

Stroud, H., Ding, B., Simon, S. A., Feng, S., Bellizzi, M., Pellegrini, M., Wang, G. L., Meyers, B. C., and Jacobsen, S. E. (2013). Plants regenerated from tissue culture contain stable epigenome changes in rice. Elife 2013.

Sultan, S. E., and Bazzaz, F. A. (1993). Phenotypic Plasticity in Polygonum persicaria . I . Diversity and Uniformity in Genotypic Norms of Reaction to Light Author ( s ): S . E . Sultan and F . A . Bazzaz Published by : Society for the Study of Evolution Stable URL : https://www.jstor.org/stabl. Evolution (N. Y). 47:1009-1031. 
Tamiru, M., Hardcastle, T. J., and Lewsey, M. G. (2018). Regulation of genome-wide DNA methylation by mobile small RNAs. New Phytol. 217:540-546.

Thiebaut, F., Hemerly, A. S., and Ferreira, P. C. G. (2019). A Role for Epigenetic Regulation in the Adaptation and Stress Responses of Non-model Plants. Front. Plant Sci. 10:246.

This, P., Lacombe, T., and Thomas, M. R. (2006). Historical origins and genetic diversity of wine grapes. Trends Genet. 22:511-519.

Thumma, B. R., Matheson, B. A., Zhang, D., Meeske, C., Meder, R., Downes, G. M., and Southerton, S. G. (2009). Identification of a cis-acting regulatory polymorphism in a eucalypt COBRA-like gene affecting cellulose content. Genetics 183:1153-1164.

Tiffney, B. H., Niklas, K. J., Editor, B., Jackson, J. B., Buss, L. W., and Cook, R. E. (1985). Population Biology and Evolution of Clonal Organisms. In (ed. Jackson, J. B.), Buss, L. W.), and Cook, R. E.), pp. 35-66. Yale University Press.

van der Graaf, A., Wardenaar, R., Neumann, D. A., Taudt, A., Shaw, R. G., Jansen, R. C., Schmitz, R. J., Colomé-Tatché, M., and Johannes, F. (2015a). Rate, spectrum, and evolutionary dynamics of spontaneous epimutations. Proc. Natl. Acad. Sci. 112:6676-6681.

van der Graaf, A., Wardenaar, R., Neumann, D. A., Taudt, A., Shaw, R. G., Jansen, R. C., Schmitz, R. J., Colomé-Tatché, M., and Johannes, F. (2015b). Rate, spectrum, and evolutionary dynamics of spontaneous epimutations. Proc. Natl. Acad. Sci. U. S. A. 112:6676-81.

Vergara, Z., and Gutierrez, C. (2017). Emerging roles of chromatin in the maintenance of genome organization and function in plants. Genome Biol. 18:1-12.

Verhoeven, K. J. F., Jansen, J. J., van Dijk, P. J., and Biere, A. (2010a). Stress-induced DNA methylation changes and their heritability in asexual dandelions. New Phytol. 185:11081118.

Verhoeven, K. J. F., Jansen, J. J., van Dijk, P. J., and Biere, A. (2010b). Stress-induced DNA methylation changes and their heritability in asexual dandelions. New Phytol. 185:11081118.

Wang, L., Ji, Y., Hu, Y., Hu, H., Jia, X., Jiang, M., Zhang, X., Zhao, L., Zhang, Y., Jia, Y., et al. (2019). The architecture of intra-organism mutation rate variation in plants Advance Access published 2019, doi:10.1371/journal.pbio.3000191.

Weigel, D., and Colot, V. (2012). Epialleles in plant evolution. Genome Biol. 13:1-6. 
Wilschut, R. A., Oplaat, C., Snoek, L. B., Kirschner, J., and Verhoeven, K. J. F. (2016). Natural epigenetic variation contributes to heritable flowering divergence in a widespread asexual dandelion lineage. Mol. Ecol. 25:1759-1768.

Wu, R., Wang, X., Lin, Y., Ma, Y., Liu, G., Yu, X., Zhong, S., and Liu, B. (2013). InterSpecies Grafting Caused Extensive and Heritable Alterations of DNA Methylation in Solanaceae Plants. PLoS One 8.

Xie, H., Konate, M., Sai, N., Tesfamicael, K. G., Cavagnaro, T., Gilliham, M., Breen, J., Metcalfe, A., Stephen, J. R., De Bei, R., et al. (2017). Global DNA Methylation Patterns Can Play a Role in Defining Terroir in Grapevine (Vitis vinifera cv. Shiraz). Front. Plant Sci. 8: $1-16$.

Young, P. R., Eyeghe-Bickong, H. A., du Plessis, K., Alexandersson, E., Jacobson, D. A., Coetzee, Z., Deloire, A., and Vivier, M. A. (2016). Grapevine plasticity in response to an altered microclimate: Sauvignon Blanc modulates specific metabolites in response to increased berry exposure. Plant Physiol. 170:1235-1254.

Zhang, H., Lang, Z., and Zhu, J. K. (2018a). Dynamics and function of DNA methylation in plants. Nat. Rev. Mol. Cell Biol. 19:489-506.

Zhang, Y.-Y., Latzel, V., Fischer, M., and Bossdorf, • Oliver (2018b). Understanding the evolutionary potential of epigenetic variation: a comparison of heritable phenotypic variation in epiRILs, RILs, and natural ecotypes of Arabidopsis thaliana. Heredity (Edinb). 121:257265.

Zhong, S., Fei, Z., Chen, Y. R., Zheng, Y., Huang, M., Vrebalov, J., McQuinn, R., Gapper, N., Liu, B., Xiang, J., et al. (2013). Single-base resolution methylomes of tomato fruit development reveal epigenome modifications associated with ripening. Nat. Biotechnol. 31:154-159.

Ziller, M. J., Hansen, K. D., Meissner, A., and Aryee, M. J. (2015). Coverage recommendations for methylation analysis by whole genome bisulfite sequencing HHS Public Access. Nat Methods 12:230-232.

Zombardo, A., Crosatti, C., Bagnaresi, P., Bassolino, L., Reshef, N., Puccioni, S., Faccioli, P., Tafuri, A., Delledonne, M., Fait, A., et al. (2020). Transcriptomic and biochemical investigations support the role of rootstock-scion interaction in grapevine berry quality. $B M C$ Genomics 21:468. 
Figure and Table Legends

Figure 1. Patterns of variation in DNA methylation and sRNA among experimental groups.

922 (A) Experimental design of replicate vines. Ungrafted-Irrigated (UG-IR; blue). Ungrafted-

923 Unirrigated (UG-UI; red). Grafted-Irrigated (GR-IR; green). Grafted-Unirrigated (GR-UI;

924 orange). Vines are planted and irrigated in a $2 \times 2$ factorial design (factors: irrigation, grafting).

925 Sampled vines are located in the center of the vineyard and three clonal replicate vines per

926 treatment block were sampled for a total of 12 clones included in this study. See also Table

927 S1. (B) Clonal replicate grapevines show distinct patterns of genome-wide DNA methylation by

928 environment and rootstock. PCA of patterns of genome-wide cytosine methylation with $\geq 20 \%$

929 difference in methylation among all individual vines. PC1 (21\%) suggests irrigation treatment is

930 the primary factor underlying variation in differential DNA methylation. PC2 indicates root

931 identity (or the condition of being grafted) is a secondary factor of differences in DNA

932 methylation. This analysis demonstrates that 'Chambourcin' grapevines can be distinguished by

933 signatures of irrigation and root identity in patterns of DNA methylation, and the condition of

934 being grafted diminishes a signal of irrigation in the 'Chambourcin' methylome. See also Table

935 S2. (C) genome-wide (in all sequence contexts) DMR counts for each experimental group

936 comparison: 31 - Ungrafted, Irrigated vs Unirrigated (left); 17 - Grafted, Irrigated vs Unirrigated

937 (center-left); 19 - Unirrigated, Ungrafted vs Grafted (center-right); 19 - Irrigated, Ungrafted vs

938 Grafted (right). See also Table S3. (D) Intragenic (+/-2.5kb; all sequence contexts) DMR counts

939 by experimental group comparison: 2 - Ungrafted, Irrigated vs Unirrigated (left); 0 - Grafted,

940 Irrigated vs Unirrigated (center-left); 2 - Unirrigated, Ungrafted vs Grafted (center-right); 1 -

941 Irrigated, Ungrafted vs Grafted (right). See also Table S3. (E) CpG sequence context only DMR

942 counts by experimental group comparison: 3 - Ungrafted, Irrigated vs Unirrigated (left); 0 -

943 Grafted, Irrigated vs Unirrigated (center-left); 3 - Unirrigated, Ungrafted vs Grafted (center-

944 right); 1 - Irrigated, Ungrafted vs Grafted (right). See also Table S3. (F) CHG sequence context

945 only DMR counts by experimental group comparison: 3 - Ungrafted, Irrigated vs Unirrigated

946 (left); 4 - Grafted, Irrigated vs Unirrigated (center-left); 204 - Unirrigated, Ungrafted vs Grafted

947 (center-right); 0 - Irrigated, Ungrafted vs Grafted (right). See also Table S3. (G) CHH sequence

948 context only DMR counts by experimental group comparison: 61 - Ungrafted, Irrigated vs

949 Unirrigated (left); 33 - Grafted, Irrigated vs Unirrigated (center-left); 6 - Unirrigated, Ungrafted 
950

951

952

953

954

955

956

957

958

959

960

961

962

963

964

965

966

967

968

969

970

971

972 Table S1. Summary of WGBS results and methylation estimates. Related to Table 2.

973 Table S2. Probe group report for genome-wide $>/=20 \%$ differential methylation. Related to

974 Figure 1B.

975 Table S3. All DMRs identified by Logistic Regression and EdgeR analyses (FDR threshold

976 0.05). Related to Figure 1, C-G.

977 Table S4. Differentially expressed small RNA identified by DESeq2 from non-normalized count

978 files. Related to Figure $1 \mathrm{H}$.

979 Table S5. Summary of all putative small RNA identified in ShortStack v3. 
bioRxiv preprint doi: https://doi.org/10.1101/2020.09.09.290072; this version posted September 10, 2020. The copyright holder for this preprint (which was not certified by peer review) is the author/funder. All rights reserved. No reuse allowed without permission.

980 Table S6. Intersection of small RNA loci and DNA methylation by sequence context. Related to 981 Results "Overview of sRNA." 
A

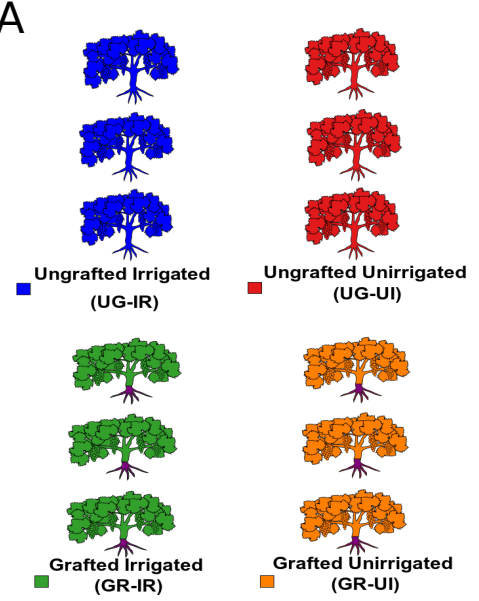

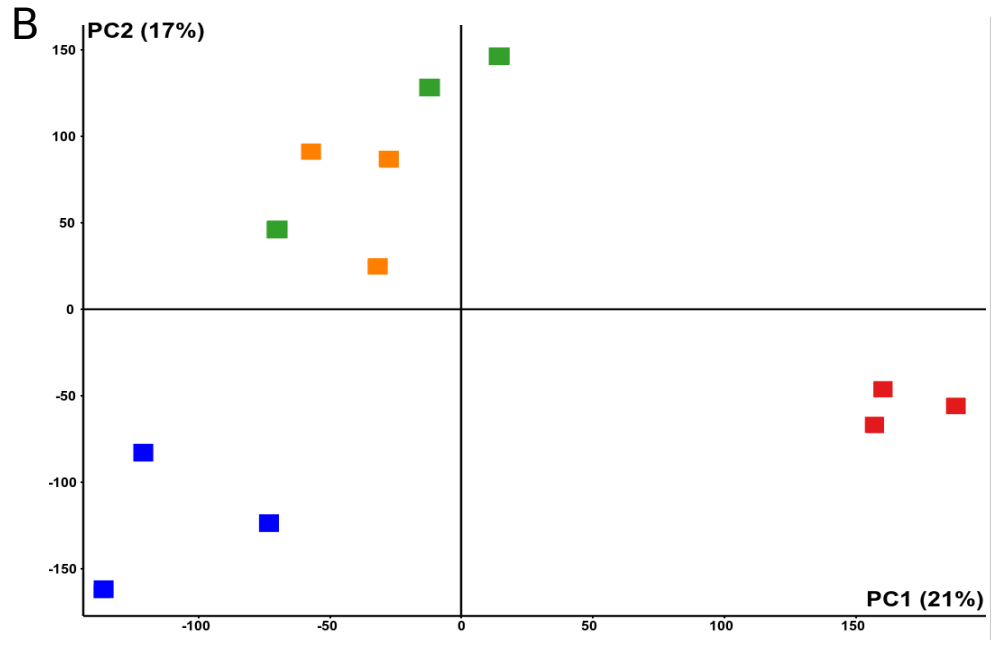

Genome Wide C

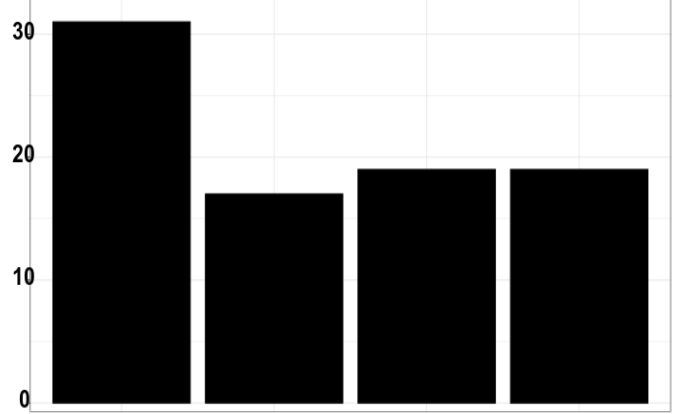

UG: IR vs UI GR: IR vs UI UI: UG vs GR IR: UG vs GR CpG

E

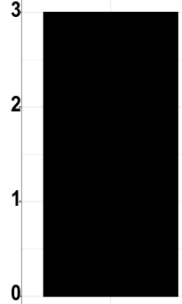

UG: IR vs UI

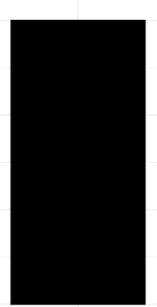

UI: UG vs GR IR: UG vs GR

\section{$\mathrm{CHH}$}

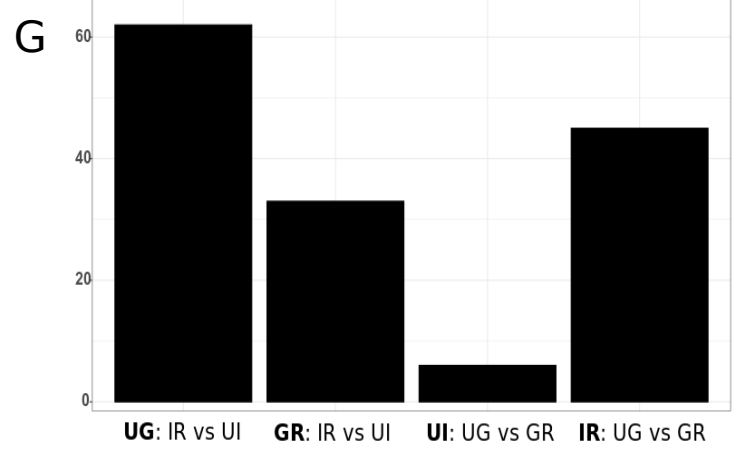

D ${ }_{4}^{\text {Intragenic }}$

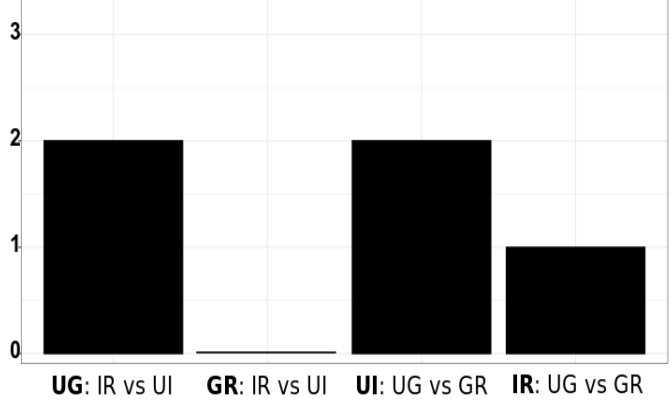

\section{CHG}

F

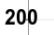

150

150

100

50

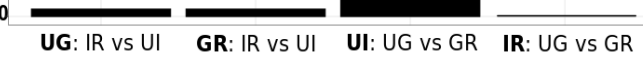

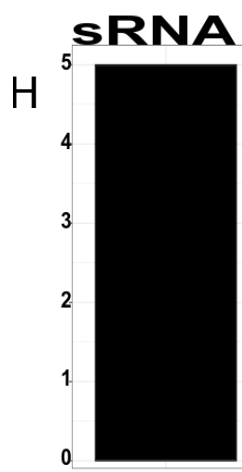

UG: IR VS UI
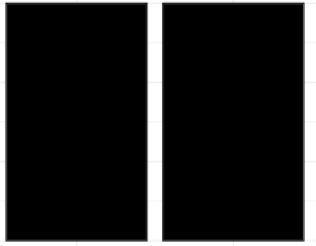

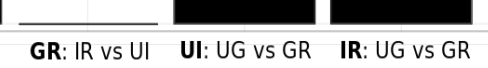


Figure 1. Patterns of variation in DNA methylation and sRNA among experimental groups.

984

985

986

987

988

989

990

991

992

993

994

995

996

997

998

999

1000

1001

1002

1003

1004

1005

1006

1007

1008

1009

1010

1011

1012

1013

(A) Experimental design of replicate vines. Ungrafted-Irrigated (UG-IR; blue). UngraftedUnirrigated (UG-UI; red). Grafted-Irrigated (GR-IR; green). Grafted-Unirrigated (GR-UI; orange). Vines are planted and irrigated in a $2 \times 2$ factorial design (factors: irrigation, grafting). Sampled vines are located in the center of the vineyard and three clonal replicate vines per treatment block were sampled for a total of 12 clones included in this study. See also Table S1. (B) Clonal replicate grapevines show distinct patterns of genome-wide DNA methylation by environment and rootstock. PCA of patterns of genome-wide cytosine methylation with $\geq 20 \%$ difference in methylation among all individual vines. PC1 (21\%) suggests irrigation treatment is the primary factor underlying variation in differential DNA methylation. PC2 indicates root identity (or the condition of being grafted) is a secondary factor of differences in DNA methylation. This analysis demonstrates that 'Chambourcin' grapevines can be distinguished by signatures of irrigation and root identity in patterns of DNA methylation, and the condition of being grafted diminishes a signal of irrigation in the 'Chambourcin' methylome. See also Table S2. (C) genome-wide (in all sequence contexts) DMR counts for each experimental group comparison: 31 - Ungrafted, Irrigated vs Unirrigated (left); 17 - Grafted, Irrigated vs Unirrigated (center-left); 19 - Unirrigated, Ungrafted vs Grafted (center-right); 19 - Irrigated, Ungrafted vs Grafted (right). See also Table S3. (D) Intragenic (+/-2.5kb; all sequence contexts) DMR counts by experimental group comparison: 2 - Ungrafted, Irrigated vs Unirrigated (left); 0 - Grafted, Irrigated vs Unirrigated (center-left); 2 - Unirrigated, Ungrafted vs Grafted (center-right); 1 Irrigated, Ungrafted vs Grafted (right). See also Table S3. (E) CpG sequence context only DMR counts by experimental group comparison: 3 - Ungrafted, Irrigated vs Unirrigated (left); 0 Grafted, Irrigated vs Unirrigated (center-left); 3 - Unirrigated, Ungrafted vs Grafted (centerright); 1 - Irrigated, Ungrafted vs Grafted (right). See also Table S3. (F) CHG sequence context only DMR counts by experimental group comparison: 3 - Ungrafted, Irrigated vs Unirrigated (left); 4 - Grafted, Irrigated vs Unirrigated (center-left); 204 - Unirrigated, Ungrafted vs Grafted (center-right); 0 - Irrigated, Ungrafted vs Grafted (right). See also Table S3. (G) CHH sequence context only DMR counts by experimental group comparison: 61 - Ungrafted, Irrigated vs Unirrigated (left); 33 - Grafted, Irrigated vs Unirrigated (center-left); 6 - Unirrigated, Ungrafted vs Grafted (center-right); 45 - Irrigated, Ungrafted vs Grafted (right). See also Table S3. (H) DE sRNA counts by experimental group comparison: 5 - Ungrafted, Irrigated vs Unirrigated (left); 0 
1014 - Grafted, Irrigated vs Unirrigated (center-left); 3 - Unirrigated, Ungrafted vs Grafted (center-

1015 right); 3 - Irrigated, Ungrafted vs Grafted (right). See also Table S4.

1016

1017

1018

1019

1020

1021

1022

1023

1024

1025

1026

1027

1028

1029

1030

1031

1032

1033

1034

1035

1036

1037

1038

1039 


\section{Genome-wide Intragenic CpG CHG}

UG: IR vs UI
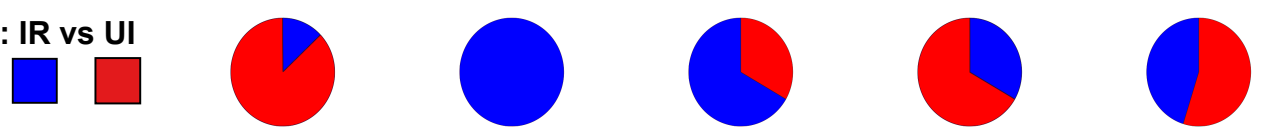

GR: IR vs UI
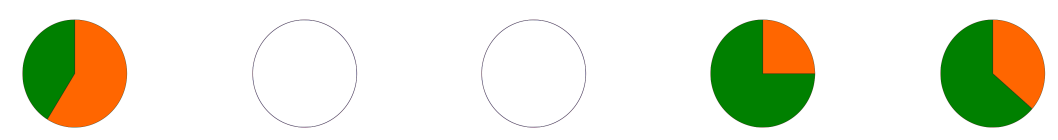

UI: UG vs GR
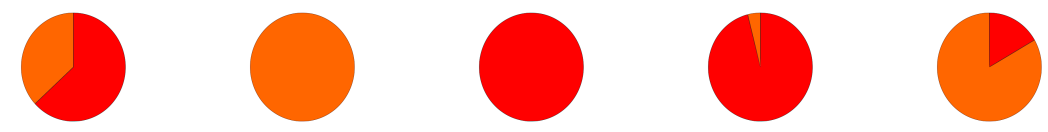

IR: UG vs GR
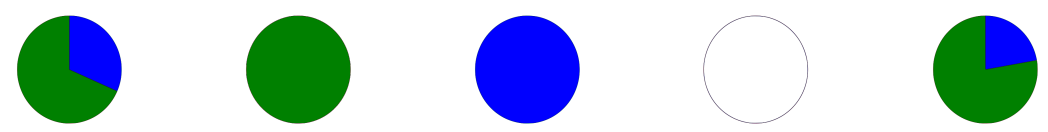

Figure 2. Proportion of DMRs in each category with elevated levels of methylation by experimental group comparisons. DMR categories are organized by column, experimental

1043 group comparisons are listed by row. Ungrafted, Irrigated vs Unirrigated: genome-wide, IR (7), 1044 UI (24); intragenic, IR (2), UI (0); CpG, IR (2), UI (1); CHG, IR (1), UI (2); CHH, IR (27), UI 1045 (34). Grafted, Irrigated vs Unirrigated: genome-wide, IR (7), UI (10); intragenic, no DMRs; 1046 CpG, no DMRs; CHG, IR (3), UI (1); CHH, IR (21), UI (12). Unirrigated, Ungrafted vs Grafted: 1047 genome-wide, UG (12), GR (7); intragenic, UG (0), GR (2); CpG, UG (3), GR (0); CHG, UG 1048 (197), GR (7); CHH, UG (1), GR (4). Irrigated, Ungrafted vs Grafted: genome-wide, UG (6), GR 1049 (13); intragenic, UG (0), GR (1); CpG, UG (1), GR (0); CHG, no DMRs; CHH, UG (10), GR 1050 (35). Empty circles indicate no DMRs. See also Table S3. 
1054 Table 1. Summary mapping statistics by replicate group.

Rootstock Treatment Mean Read Length (bp) Total Read Length (bp) Fold Coverage

\begin{tabular}{llclc}
\hline Ungrafted & Irrigated & 110 & $9,994,970,903$ & 21 \\
Ungrafted & Unirrigated & 107 & $8,082,919,551$ & 17 \\
Grafted & Irrigated & 110 & $9,328,021,049$ & 20 \\
Grafted & Unirrigated & 108 & $10,548,329,716$ & 22 \\
\hline
\end{tabular}

1055

1056

1057

1058

1059

1060

1061

1062

1063

1064

1065

1066

1067

1068

1069

1070

1071

1072

1073

1074

1075

1076

1077 
1078 Table 2. Estimated methylation levels by individual within replicate groups.

Genome-wide

Rootstock Irrigation Row Block Vine methylation $\mathrm{CpG} \quad \mathrm{CHG} \quad \mathrm{CHH}$

\begin{tabular}{|c|c|c|c|c|c|c|c|c|}
\hline \multirow[t]{3}{*}{ Ungrafted } & Full & 12 & B & 2 & $10.8 \%$ & $45.5 \%$ & $22.6 \%$ & $4.6 \%$ \\
\hline & & 12 & B & $3 *$ & $11.5 \%$ & $45.1 \%$ & $23.3 \%$ & $5.1 \%$ \\
\hline & & 12 & B & $4 *$ & $11.0 \%$ & $45.2 \%$ & $22.7 \%$ & $4.7 \%$ \\
\hline \multirow[t]{3}{*}{ Ungrafted } & None & 13 & $\mathrm{D}$ & 2 & $10.8 \%$ & $43.7 \%$ & $21.1 \%$ & $5.0 \%$ \\
\hline & & 13 & $\mathrm{D}$ & $3 *$ & $10.5 \%$ & $43.9 \%$ & $21.4 \%$ & $4.6 \%$ \\
\hline & & 13 & $\mathrm{D}$ & $4^{*}$ & $10.9 \%$ & $45.3 \%$ & $23.1 \%$ & $4.7 \%$ \\
\hline \multirow[t]{3}{*}{ Grafted } & Full & 12 & $\mathrm{D}$ & 2 & $10.9 \%$ & $44.7 \%$ & $21.8 \%$ & $4.8 \%$ \\
\hline & & 12 & $\mathrm{D}$ & $3 *$ & $9.1 \%$ & $40.0 \%$ & $17.6 \%$ & $4.1 \%$ \\
\hline & & 12 & $\mathrm{D}$ & $4 *$ & $11.3 \%$ & $45.3 \%$ & $23.3 \%$ & $4.7 \%$ \\
\hline \multirow[t]{3}{*}{ Grafted } & None & 13 & B & 2 & $10.9 \%$ & $44.3 \%$ & $21.9 \%$ & $4.8 \%$ \\
\hline & & 13 & B & $3 *$ & $11.0 \%$ & $43.6 \%$ & $22.1 \%$ & $4.8 \%$ \\
\hline & & 13 & B & $4 *$ & $11.5 \%$ & $44.9 \%$ & $23.6 \%$ & $5.0 \%$ \\
\hline
\end{tabular}

